\title{
Acute urinary retention: analysis of 500 cases in the urology department of the Conakry teaching hospital in Guinea
}

\begin{abstract}
Objective: To evaluate the epidemiology and clinical aspects of Acute Urinary retention (AUR) and the current practice in its management in Guinea.

Patients and methods: This is a retrospective study of 500 cases of AUR in a 3 years period from January 2015 to December 2017).

Results: AUR represented $69,80 \%(\mathrm{n}=500)$ of the total number of urological emergencies in our department in the study period. The mean age was 60, 6 year (Range 2 months to 95 years). The sex ratio was M.F was 26.72 . The main etiologies of urinary retentions were prostatic tumors $(68.53 \%)$ and urethral strictures $(20.64 \%)$. Urethral catheterization was the most used bladder drainage method in emergency.
\end{abstract}

Conclusion: Urine retention is the most common urological emergency in our department. Prostatic tumors are the main etiology. Its emergency management is based on bladder drainage.

Keywords: acute urine retention, emergency, prostate neoplasm, urethral stricture, bladder drainage
Volume 7 Issue 5 - 2019

\author{
Daouda Kanté,' Thierno Mamadou Oury,' \\ Mamadou Diawo Bah,' Alpha Boubacar Bah,'2 \\ Ricardo Gnami,' Abdoulaye Bobo Diallo' \\ 'Service d'Urologie-Andrologie, CHU de Conakry, Guinea \\ ${ }^{2}$ Département de Chirurgie Générale, Service de chirurgie \\ générale, CHU de Conakry, Guinea
}

Correspondence: Alpha Boubacar BAH, Service de Chirurgie Générale, Hôpital Ignace Deen

CHU de Conakry Guinée, BP: 615 Conakry, Guinea, Tel +224660 I2 I2 I2, Email alphbahns@gmail.com

Received: July 21, 2019 | Published: September 09, 2019
Abbreviations: AUR, acute urinary retention; AIDS, acquired immune deficiency syndrome

\section{Introduction}

Acute Urinary Retention (AUR) is commonly seen in the emergency department, most often in older men with benign prostatic hypertrophy. ${ }^{1}$ It is defined as a sudden and painful inability to void voluntarily and presents unique assessment and treatment challenges in the emergency department setting. ${ }^{1}$ Painless AUR is rare and is usually associated with CNS pathology. Over $10 \%$ of men in their seventh decade will experience AUR over a 5-year period and the risk increases to one in three over 10 years. $^{2}$ The condition is distressing to the affected individuals and the clinical examination reveals a tensile pubic mass whose palpation accentuates the urge to urinate. It's a urological emergency, requiring adequate management based on bladder decompression by catheterization and quickly addressing the etiology. ${ }^{2}$ The purpose of this study was to highlight the epidemiology and current management practice of AUR in the Urology-Andrology department of the University Hospital of Conakry.

\section{Material and methods}

This retrospective study was approved by the University of Conakry Teaching hospital Ethical Committee. We collected data from all patients who were diagnosed with AUR from clinical history and physical examination from January 2015 to December 2017 in the Urology-Andrology department. The data collected include demographics, clinical history, etiologies and the emergency treatment used. Patients whose medical records were missing were excluded.

\section{Results}

The total number of patients included in our study was five hundred, accounting for $69.80 \%$ of urological urgencies managed in our department in the study period. The mean age of our patients was 60.6 years ranging from 2 months to 95 years. Male patients were the most affected $(96.39 \%)$ with a sex ratio of 26.72 and $63.73 \%(n=318)$ of our patients were over 60 years old. The age distribution is shown in Table 1. Farmers and labor workers were more affected, $46.31 \%$ and $20 \%$ respectively. In terms of geographical origin, 311 patients $(62.32 \%)$ came from Conakry the capital, and the remaining $37.68 \%$ were referred from rural regions of the country. The causes of acute urine retention were dominated by prostatic tumors, followed by urethral stenosis (Table 2). We didn't find any case of AUR caused by an urinary tract infection. All our patients underwent emergency urinary bladder drainage using a urethral catheter in $69.34 \%(n=346)$ of cases and suprapubic cystotomy in $30.66 \%(n=154)$ of cases.

Table I: Age distribution of acute urinary retention

\begin{tabular}{lll}
\hline Age groups & Number of patients & Percentage (\%) \\
\hline $0-19$ & 18 & 3,40 \\
$20-39$ & 56 & 11,22 \\
$40-59$ & 108 & 21,65 \\
$60-79$ & 249 & 49,91 \\
$80-99$ & 69 & 13,82 \\
\hline
\end{tabular}


Table 2: Etiologies of AUR

\begin{tabular}{lll}
\hline Etiologies & $\begin{array}{l}\text { Number } \\
\text { of patients }\end{array}$ & $\begin{array}{l}\text { Percentage } \\
\text { (\%) }\end{array}$ \\
\hline $\begin{array}{l}\text { Prostatic neoplasms } \\
\text { and Benign Prostate } \\
\text { Hyperplasia }\end{array}$ & 342 & 68,53 \\
$\begin{array}{l}\text { Urethral stricture } \\
\text { Bladder calculus }\end{array}$ & 103 & 20,64 \\
Neurogenic dysfunctions & 18 & 4,01 \\
Others & 17 & 3,61 \\
Total & 500 & 3,21 \\
\end{tabular}

Neurogenic dysfunctions: 15 cases of strokes, 2 cases of Post-opertative, and I case of AIDS

Others: 4 cases of posterior urethral valves, 3 cases of phimosis, 5 cases of bladder neck sclerosis, 3 cases of blunt abdominal injury, 2 cases of bladder tumors.

\section{Discussion}

Acute urine retention is the most common urological emergency in our study (69.80\%). The same observation was made by Fall B et al., ${ }^{3}$ in Senegal, where AUR accounts for 53\% of urological emergencies. In our countries, it constitutes the main mode of revelation of prostate neoplasms, benign prostatic hyperplasia and urethral stricture. In the low socio-economic setting, the frequent use of traditional medicine, and the taboo that surrounds urogenital diseases leads the majority of these patients to seek medical attention at a later stage when complications have already occurred. In the Western countries, acute urine retention is not the most frequent urological urgency, ${ }^{3}$ accounting for only $22 \%$ of the reasons for consultation in France, according to the Mondet et al., ${ }^{4}$ study. The mean age and the predominance of men at least 60 years old is concordant with previous observations made by Diallo MB et al., ${ }^{1}$ who reported an average age of 58.6 years and a higher frequency of AUR in patients over 60 years of age. In Minnesota, Jacobsen SJ et al., ${ }^{5}$ reported in a study of patients with benign prostatic hyperplasia that the relative risk of first episode RAU increases with age; a 60 -year-old man has a $23 \%$ chance of having a UAR within 20 years. The socio- professional category in our study (more frequent in farmers and labour worked), is only a reflection of the predominance of these sectors of activity in our country.

While most patients $(62.4 \%)$ came from Conakry, fewer patients residing in remote areas of Guinea were referred to our ward. This underestimated number underline the lack of basic urological training of health workers in our peripheral health structures and may indicate that AUR is underreported in non-urban areas. The etiology of UAE is essentially dependent on the age and sex of the patient. ${ }^{2,6}$ The etiologies are distinguished in two groups, obstructive and neurogenic dysfunctions. ${ }^{2}$ The predominance of benign prostatic hyperplasia, carcinoma of the prostate and urethral stricture as a cause of AUR is well documented in the African literature..$^{3,7,8}$ The other etiologies were cerebrovascular accidents, post-operative AUR, and one case of AIDS. No postpartum reflex AUR was observed in our serie in contrast to Guiheneuf $\mathrm{A}^{9}$ findings. The most employed method in relieving retention was urethral catheterization in $69.34 \%$ of cases.
Because of its frequent use, this procedure must be taught and practiced according to a well-established protocol with a strict respect of the different stages to lessen the risk of inherent complications like pain, urethral trauma or infection. ${ }^{10}$ Fall $\mathrm{B}$ et al., ${ }^{3}$ also point out that the relatively long durations of carrying an undwelling urinary catheters required by the whole etiologic surgical treatment is a cause of deterioration of quality of life and the whole economic cost of the management of the condition. ${ }^{11,12}$

\section{Conclusion}

Acute urine retention is the most common urological emergency in our country. It mainly affects the aging man carrying a prostatic tumor. Its emergency management is based on bladder drainage dominated by urethral catheterization.

\section{Acknowledgements}

None.

\section{Conflicts of interest}

The auhtor declares there is no conflict of interest.

\section{References}

1. Diallo MB, Cisse A, Camara ND, et al. Urinary retention of urine in 273 cases. Guinée Méd. 1996;10:25-29.

2. Goldbatt L, Delmas V, Khoury R, et al. Urinary retention of urine. Encycl Méd Chir Urgences. 2000;24-182-A-10:8.

3. Fall B, Diao B, Fall PA, et al. Urological emergencies at the Dakar university teaching hospital: epidemiological, clinical and therapeutic features. Prog Urol. 2008;18(10):650-653.

4. Mondet F, Chartier-Kastler E, Yonneau L, et al. Epidemiology of urological urgencies in University Hospital Center. Prog Urol. 2002; $12: 437-442$.

5. Jacobsen SJ, Jacobson DJ, Girman CJ, et al. Natural history of prostatism: risk factors for acute urinary retention. J Urol. 1997;158(2):481-487

6. Fontaine E, Thomas L, Sonigo B. Urinary retention of urine. Rev Prat. 2002;52(17):1943-1946.

7. Diallo AB, Bah I, Diallo TMO, et al. Le profil des urgences urologiques au CHU de Conakry, Guinée. Prog Urol. 2010;20:214-218

8. Rantomalala HYH, Rakotoarijaona A, Rajaonanahary TMA. Les rétentions aigues des urines : aspects épidemio-cliniques et thérapeutiques. Méd Afr Noire. 2006;53(8):471-475.

9. Guiheneuf A, Weyl B. Rétention aiguë d'urine du postpartum. A propos de deux cas et revue de la littérature. J Gynécol Obstét Biol Reprod. 2008;37(6):614-617.

10. Bigot P, Roupret M, Orsat M, et al. Assessment of practical skills at the end of the second cycle of medical studies: example of drainage of the lower urinary tract. Prog Urol. 21008;18(2):125-131.

11. Ikuerowo SO, Ogunade AA, Ogunlowo TO, et al. The burden of prolonged indwelling catheter after acute urinary retention in IkejaLagos, Nigeria. BMJ. 2007;7:16.

12. Thomas K, Oades G, Taylor-Hay C, Kirby RS. Acute urinary retention: what is the impact's on patient quality of life? BJU Int. 2005;95(1):7276. 